\title{
Investigation of Stability Alarming for Retaining Wall Structures with Damage
}

\author{
Qian Xu \\ School of Civil Engineering and Architecture, Shaanxi University of Technology, Hanzhong, Shaanxi 723000, China \\ Correspondence should be addressed to Qian Xu; xuqian20121601014@163.com
}

Received 21 April 2017; Revised 16 October 2017; Accepted 7 November 2017; Published 3 December 2017

Academic Editor: Giosuè Boscato

Copyright (C) 2017 Qian Xu. This is an open access article distributed under the Creative Commons Attribution License, which permits unrestricted use, distribution, and reproduction in any medium, provided the original work is properly cited.

\begin{abstract}
To warn of the stability of retaining wall structures with damage, a simplified mechanical model and a finite element model of this retaining wall-soil coupling system are established. Via finite element model updating, a baseline finite element model of the wall-soil system is acquired. A damage alarming index ERSD (Energy Ratio Standard Deviation) is proposed via the wavelet packet analysis of a virtual impulse response function of dynamic responses to this baseline finite element model. The internal relationships among the alarming index, earth pressure, and damage stability of the wall are analyzed. Then, a damage stability alarming method for the retaining walls is advanced. To verify the feasibility and validity of this alarming method, vibration tests on the baseline finite element model of a pile plate retaining wall are performed. The ERSD is used as an alarm for the damage stability of the wall. Analysis results show that, with an increase in the ERSD, the stability of the wall changes from a stable state to an unstable one. The wall reaches a critical stable state when the alarming index reaches its threshold value. Thus, the damage stability of this pile plate retaining wall can be alarmed via ERSD.
\end{abstract}

\section{Introduction}

Retaining wall structures, which are a common type of retaining structures, are mainly used to support foundation ditches and stabilize slopes. Hence, retaining wall structures are widely used in building engineering, transportation engineering, underground engineering, and related fields. However, a retaining wall may lose stability or collapse under the influences of many factors (such as variations in temperature or humidity, material degradation, and load variation). Additionally, some terrible accidents may occur once the wall collapses. In 2008, an underground wall collapsed in Hangzhou City of Jiangsu Province, China, causing 45 deaths, many injures, and huge economic losses. In 2014, a retaining wall collapsed in Qingdao City of Shandong Province, China, causing 18 deaths and several injures. In 2016, a wall collapsed in Quanzhou City of Fujian Province, China, causing 2 deaths and 6 injuries. Thus, much more attention is now being paid to stability of retaining wall structures caused by damage to avoid or reduce similar accidents in the future.

The stability of retaining walls includes both static and dynamic stability. To date, studies of the static stability of retaining walls have investigated influences such as wall height, wall width, uniform loads, and the cohesion and internal friction angle of the backfill on the static stability of retaining walls. Vijayakumer et al. analyzed the static stability of retaining walls at Dewarwadi of Belagavi, India. They found that the existing walls were safe but uneconomical and oversized. To save materials, optimal dimensions of retaining walls were proposed [1]. Liu and Chen analyzed the stability of a new type of walls with relieving plates by the FEM (Finite Element Method). The width of the relieving plates influenced the stability of the walls, and a reasonable value of relieving-plate width should be considered in real engineering [2,3]. Liu et al. analyzed influences such as wall height, uniform loads, and the internal friction angle of backfill on static stability of a cantilever retaining wall [4]. To improve the stability of counterfront retaining walls, a relief shelf was fixed in a counterfort retaining wall. Tonne and Mohite analyzed the influence of position of the relief shelf on the satiability of the wall [5]. Akihiro et al. studied the antisliding stability of a dry masonry block retaining wall with resistance plates. The resistance plates contributed well to reducing the greater horizontal earth pressure acting on 
the block body and to improving the stability of the wall [6]. To verify the structural performance of masonry walls, nondestructive tests on a masonry wall with multileaves were carried out by Boscato et al. The structural integrity, the efficacious of consolidating intervention, and the potential performance mechanisms of masonry walls with different complex multileaves were evaluated $[7,8]$. Investigations on dynamic stability of the walls studied the effects of earthquakes or other dynamic loads on the wall stability. Wang et al. analyzed the antioverturning stability of a retaining wall by the pseudodynamic method and investigated the effects of the wall inclination, wall friction angle, and soil friction angle on the antioverturning stability of the wall. Both horizontal and vertical seismic acceleration decreased the overturning stability of the retaining wall [9]. Based on the multiblock upper-bound method, Huang et al. proposed a theoretical model of seismic rotational stability of a gravity retaining wall with consideration of the influence of embedment depth $[10,11]$. Pain et al. analyzed the rotational stability of a gravity retaining wall on rigid foundation via the limit equilibrium method [12]. Anindya et al. studied the antisliding stability of a retaining wall by a modified pseudodynamic method under the effect of seismic loads [13]. Syed and Deepankar analyzed the stability of waterfront retaining walls under the effects of seismic loads and tsunamis. In comparison with the studies presented, many conclusions were drawn [14]. Considering the influences of time-frequency effects and seismic wave duration on the stability of retaining walls, Yang et al. proposed a time-frequency method to analyze the seismic stability of the retaining wall and studied the effects of internal frictional angle of the backfill, seismic intensity, and frequency of earthquake waves on seismic stability. They also provided valuable references for the timefrequency seismic design of other retaining structures [15]. Zhang et al. investigated the antisliding stability of a retaining wall with prestressed ropes under seismic loads based on the kinematical approach of the upper-bound theorem. It was found that enhancing the prestressed rope force effectively improved the critical yield acceleration factor [16]. Li et al. analyzed the seismic stability of gravity retaining walls based on the upper-bound theorem of the limit analysis method. In comparison with vertical acceleration, horizontal acceleration had much more influence on the wall stability. However, under certain conditions, the effects of vertical acceleration were considerably large and could not be neglected [17]. Zhou et al. investigated the seismic stability of a water front retaining wall via the pseudodynamic method. The effects of seismic acceleration, amplification factor, wall height, physicomechanical parameters of backfill soil, and hydrodynamic pressure acting on the water front retaining wall on antisliding safety factors and antioverturning safety factors of the retaining wall were quantitatively analyzed. It was concluded that the stability of the retaining wall decreased when the earthquake increased its speed, the water level increased, and the internal friction angle decreased [18]. Du et al. sought the relationship between safety factors of retaining walls and reliability indexes and found that the reliability index increased with the increase in wall safety factors [19]. Via the interval analysis method, Zhao et al. established a nonprobabilistic reliability analysis mode for the stability of retaining walls. The stability state of walls was detected by nonprobabilistic reliability indexes [20]. Based on the limit equilibrium analysis, Song et al. investigated the stability analysis method for geocell-reinforced retaining walls. The global stability of a geocell-reinforced retaining wall was predicted [21]. Zhang et al. proposed a simplified method for evaluating the antioverturning stability of a rigid retaining wall [22]. From the above, previous studies on the stability of retaining walls have investigated the influence of various factors (such as wall height, wall width, cohesion and internal frictional angle of backfill, and acceleration) on the stability of retaining walls or proposed updated calculation methods for the wall stability. There are almost no studies regarding the effects of damage within retaining walls on the stability of the walls. There is also no damage stability alarming method for retaining walls. Thus, proposing a damage stability alarming method for retaining wall structures is critical.

In this paper, based on the mechanical analysis of a retaining wall-soil coupling system, technology of finite element model updating, and damage alarming index, the internal relationships among the alarming index, earth pressure, and damage stability of the wall are analyzed. Then, a damage stability alarming method for retaining wall structures is advanced. And the feasibility and validity of this stability alarming method are verified.

\section{Simplified Mechanical Model of a Retaining Wall-Soil Coupling System}

Mechanical analysis of a retaining wall-soil system is performed. The interaction between the wall and backfill includes the normal pressure (earth pressure) and tangential friction. Under low strain excitation, it is assumed that both the normal pressure and tangential friction can be replaced with those under static equilibrium [23]. In addition, it is also assumed that the backfill is compressed greatly and that the backfill behind the retaining wall vibrates together with the wall under low strain excitation [24]. Thus, the earth pressure can be equivalent to a series of normal spring element components, and the friction can be equivalent to a series tangential spring element component [25].

According to the literature [25], it is assumed that the stiffness of normal springs can be equivalent to the coefficient of a subgrade reaction of the backfill and that the stiffness of the tangential springs is a function of the stiffness of normal springs. Sometimes the stiffness of spring elements is called additional stiffness. Thus, the additional stiffness includes the normal stiffness $K^{n}$ and tangential stiffness $K^{\tau}$. According to Winkler's assumption [26], the coefficient of subgrade reaction $K_{S}$ is relevant to itself $\left(K_{S 0}\right)$, the type of backfill, and the displacement of backfill. Thus, the coefficient of subgrade reaction $K_{S}$ can be expressed as follows:

$$
K_{S}=K_{S 0} z^{t}
$$

where $z$ is the depth of backfill and $K_{S 0}$ and $t$ are undetermined parameters. 
Thus, the normal stiffness $K^{n}=K_{S}=K_{S 0} z^{t}$ and the tangential stiffness $K^{\tau}$ can be expressed as follows:

$$
K^{\tau}=\left(K^{n}\right)^{p}
$$

where $p$ is an undetermined parameter.

According to the literature [26], the additional mass $M_{S}$ can be expressed as follows:

$$
M_{S}(z)=\frac{z}{3.5} \times \frac{8}{27} \rho D=0.0847 z \rho D,
$$

where $z$ and $\rho$ are the height and density of the backfill, respectively, and $D$ is the equivalent diameter of a unit circle.

Similar to (2), (3) can be rewritten as follows:

$$
M_{S}(z)=M_{S 0} z^{S},
$$

where $M_{S 0}$ and $S$ are undetermined parameters.

The Rayleigh damping is used to reflect the damping characteristics of the retaining wall-soil coupling system. The Rayleigh damping is determined by the mass damping coefficient $\alpha_{S}$ and stiffness damping coefficient $\beta_{S} . \alpha_{S}$ and $\beta_{S}$ can be, respectively, expressed as follows:

$$
\begin{aligned}
& \alpha_{S}=\frac{2 \xi \omega_{i} \omega_{j}}{\omega_{i}+\omega_{j}}, \\
& \beta_{S}=\frac{2 \xi}{\omega_{i}+\omega_{j}},
\end{aligned}
$$

where $\alpha_{S}$ and $\beta_{S}$ are undetermined parameters, $\xi$ is the damping ratio, and $\omega_{i}$ and $\omega_{j}$ are the $i$ th and the $j$ th inherent frequency, respectively.

Based on these parameters $\left(K_{S 0}, t, p, M_{S 0}, S, \alpha_{S}, \beta_{S}\right)$, the simplified mechanical model of the retaining wall-soil system is acquired, as shown in Figure 1.

\section{Finite Element Model Updating for the Retaining Wall-Soil Coupling System}

Based on the simplified mechanical model of this retaining wall-soil coupling system, a finite element model of the wall-soil system is established by the ANSYS program. The wall is simulated by the Solid 45 elements. The interaction between the wall and the backfill changes when the backfill is damaged. However, the mass of the backfill is constant when the backfill is damaged. Thus, the backfill (additional mass) is simulated by the Mass 21 elements; the interaction (additional stiffness) between the wall and backfill is simulated by the Combining 14 elements, and the damping of this finite element model is the Rayleigh damp. The deformation at the bottom of this model is restrained, and the lateral displacement of the model is restrained.

Generally, the finite element model, which is directly established on the basis of undetermined parameters $\left(K_{S 0}, t\right.$, $\left.p, M_{S 0}, S, \alpha_{S}, \beta_{S}\right)$, cannot reflect the true dynamic characteristics of the wall-soil system. Thus, this finite element model should be improved. Based on modal tests and finite element modal analysis, this finite element model is updated.

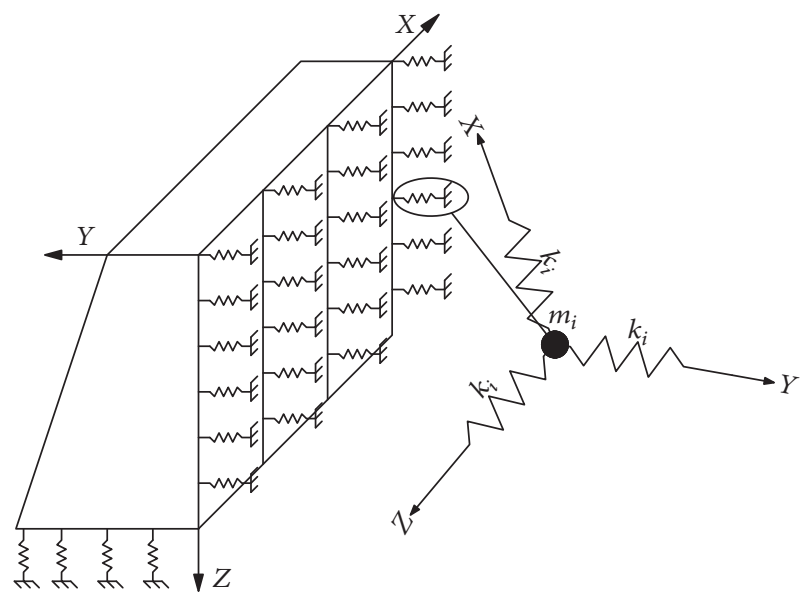

FIGURE 1: Simplified mechanical model of a retaining wall-soil system.

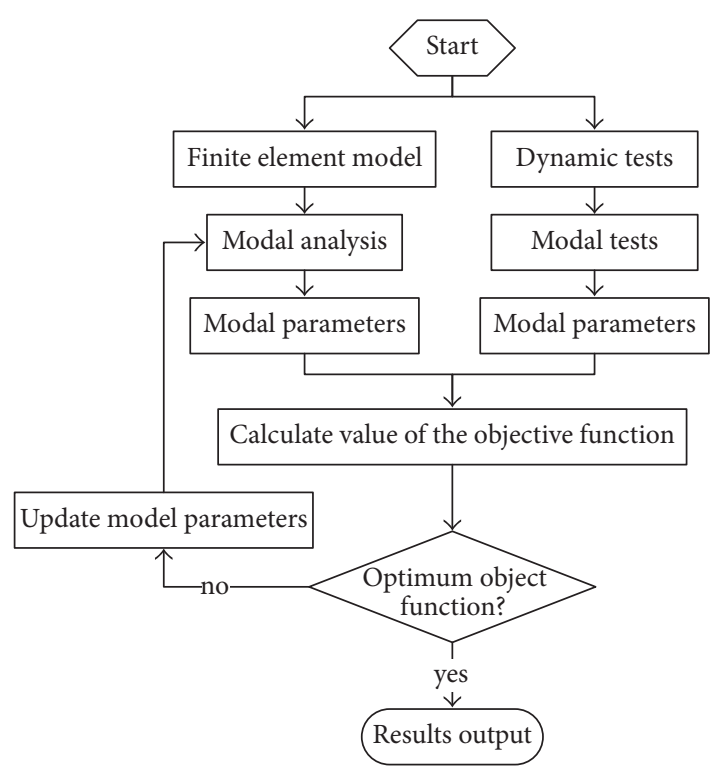

FIGURE 2: Flow chart of the finite element model updating process.

According to the theory of finite element model updating $[27,28]$, design variables reach optimum values when objective functions (such as frequencies, mode shapes, and displacement) reach minimum values. In this article, the design variables are undetermined parameters $\left(K_{S 0}, t, p\right.$, $M_{S 0}, S, \alpha_{S}, \beta_{S}$ ), and the objective functions can be selected as frequencies, mode shapes, or both. The finite element model updating process of the retaining wall-soil coupling system is shown in Figure 2.

\section{Damage Alarming Index}

According to the wavelet packet damage alarming theory [29], under constant excitations, the wavelet packet decomposition of the response signals to the damaged and undamaged structures is performed. Then, the damage state of the structure can be detected by comparing the same 
subfrequency band signal to the damaged and undamaged structures. However, identifying damage within structures via the wavelet packet decomposition of the response signal is neither precise nor efficient. Thus, the wavelet frequency band energy spectrum is introduced. Under constant excitations, the energy of every subfrequency band signal is calculated via the wavelet packet decomposition. The alarming information can be obtained via comparing the energy of the same subband [30, 31]. However, ES (the wavelet packet frequency band energy spectrum), which is obtained via wavelet packet decomposition of the responses to structures, varies with the changes in excitations. Meanwhile, ES obtained via wavelet packet decomposition of a virtual impulse response function of responses to structures never changes with the variation in stimulations [30]. Thus, ES is obtained via the wavelet packet decomposition of a virtual impulse response function of responses to the retaining wall. Then, FFVS (the wavelet packet feature frequency band vector spectrum) is created, and DFVS (the wavelet packet damage feature vector spectrum) is proposed. Based on DFVS, an alarming index is proposed.

Wavelet packet decomposition of a virtual impulse response function $H$ can be expressed as follows:

$$
H=\sum_{J=1}^{2^{I}} H_{J}=H_{1}+H_{2}+\cdots+H_{2^{I}},
$$

where $H_{J}$ is the virtual impulse response function component on subfrequency band and $I$ is the number of wavelet packet decomposition layers.

In light of the wavelet packet energy spectrum theory [30], the energy of a virtual impulse response function component $E_{J}$ can be expressed as follows:

$$
E_{J}=\sum\left|H_{J, r}\right|^{2} \quad(r=1,2, \ldots, l),
$$

where $l$ is the number of signal simple points.

Thus, $\mathbf{E}_{I}$ (ES of the signal $H$ ) is acquired, and $\mathbf{E}_{I}$ can be expressed as follows:

$$
\mathbf{E}_{I}=\left[\begin{array}{llllll}
E_{1} & E_{2} & \cdots & E_{J} & \cdots & E_{2^{I}}
\end{array}\right]^{T} .
$$

Next, define the energy ratio $\mathrm{ER}_{J}$ as follows:

$$
\mathrm{ER}_{J}=\frac{E_{J}}{\sum_{J=1}^{2^{I}} E_{J}} .
$$

Then, a new energy ratio sequence $\mathbf{E R}_{I}$ is obtained. $\mathbf{E R}_{I}$ can be expressed as follows:

$$
\mathbf{E R}_{I}=\left[\begin{array}{llllll}
\mathrm{ER}_{1} & \mathrm{ER}_{2} & \cdots & \mathrm{ER}_{J} & \cdots & \mathrm{ER}_{2^{I}}
\end{array}\right]^{T} .
$$

$\mathbf{E R}_{I}$ can be sorted from large to small according to energy ratio values, yielding a new energy ratio sequence $\mathbf{E R}_{G}$ :

$$
\begin{aligned}
& \mathbf{E R}_{G}=\left[\begin{array}{llllll}
\mathrm{ER}_{1} & \mathrm{ER}_{2} & \cdots & \mathrm{ER}_{J} & \cdots & \mathrm{ER}_{2^{I}}
\end{array}\right]^{T} \\
& \left(\mathrm{ER}_{J} \geq \mathrm{ER}_{J+1}\right),
\end{aligned}
$$

where $\mathbf{E R}_{G}$ is referred to as ERS (the wavelet packet frequency band energy ratio spectrum).

Due to the interference of measurement noise, it is impossible to completely detect the variation of every energy ratio. Generally, only those energy ratios that are much larger are easily identified. Thus, the top $P$ frequency bands with larger energy ratios are selected to detect alarming information. Let $\varepsilon_{P} \leq \varepsilon_{0}$ :

$$
\varepsilon_{P}=\sum_{\mathrm{Q}=1}^{P} \mathrm{ER}_{\mathrm{Q}} \quad\left(\mathrm{ER}_{\mathrm{Q}} \in \mathrm{ER}_{\mathrm{G}}\right),
$$

where $\varepsilon_{P}$ is the relative cumulative energy ratio and $\varepsilon_{0}(0.85 \sim$ $0.95)$ is a threshold value. It is via $\varepsilon_{0}$ that the top $P$ energy ratios in $\mathbf{E R}_{G}$ can be determined. The energy ratio changes in these $P$ frequency bands can be used as an alarm for the stability of retaining walls. Nevertheless, the effects of residual frequency bands in $\mathbf{E R}_{G}$ on the stability alarm should not be ignored. Thus, the residual frequency bands are merged into one band. This band is called the residual frequency band. Then, the energy ratio of the residual frequency band $\mathrm{ER}_{P+1}$ is defined as follows:

$$
\mathrm{ER}_{P+1}=1-\sum_{\mathrm{Q}=1}^{P} \mathrm{ER}_{\mathrm{Q}} .
$$

These $(P+1)$ frequency bands are called feature frequency bands. Then, the FFVS $\mathbf{E R}_{P+1}$ is defined as follows:

$$
\mathrm{ER}_{P+1}=\left[\begin{array}{lllll}
\mathrm{ER}_{1} & \mathrm{ER}_{2} & \cdots & \mathrm{ER}_{p} & \mathrm{ER}_{P+1}
\end{array}\right]^{T} .
$$

On the basis of $\mathbf{E R}_{P+1}$, the energy ratio deviation $\mathrm{ERD}_{K}$ is defined as follows:

$$
\mathrm{ERD}_{K}=\left|\mathrm{ER}_{K}^{u}-\mathrm{ER}_{K}^{d}\right| \quad(K=1,2, \ldots, P+1),
$$

where $\mathrm{ER}_{K}^{u}$ and $\mathrm{ER}_{K}^{d}$ are the energy ratios of the $K$ th feature frequency band of structures under initial conditions (without damage) and those under operating conditions, respectively.

Then, DFVS ERD $\mathbf{E P}_{P+1}$ is defined as follows:

$$
\mathbf{E R D}_{P+1}=\left[\begin{array}{llllll}
\mathrm{ERD}_{1} & \mathrm{ERD}_{2} & \cdots & \mathrm{ERD}_{P} & \mathrm{ERD}_{P+1}
\end{array}\right]^{T} .
$$

On the basis of $\mathbf{E R D}_{P+1}$, an alarming index, Energy Ratio Standard Deviation (ERSD), is proposed, and ERSD is expressed as follows:

$$
\text { ERSD }=\sqrt{\frac{\sum_{K=1}^{P+1}\left(\mathrm{ERD}_{K}\right)^{2}}{P+1}} .
$$

There is no damage within retaining wall structures when $\mathrm{ERSD}=0$, and there is damage when ERSD $>0$.

\section{Damage Stability Alarming Method for Retaining Wall Structures}

The stability of a retaining wall is decided by the earth pressure loading on the wall. The changes in earth pressure cause changes of stability of the wall. The retaining wall will reach a critical stable state when the earth pressure reaches the threshold value. Thus, analysis of the earth pressure is the key to stability alarming for the retaining wall. 


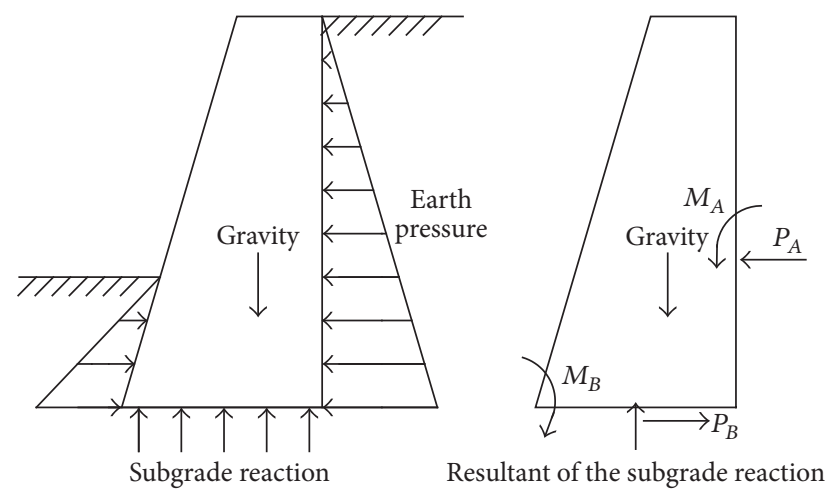

Figure 3: Schematic of the stability analysis of retaining wall structures.

5.1. Relationship between the Earth Pressure and the Stability of the Retaining Wall. Stability of the retaining wall includes two parts, antisliding stability and antioverturning stability. Thus, the antisliding stability and antioverturning stability determine whether the wall is stable. Antisliding safety factor $K_{s}$ and antioverturning safety factor $K_{t}$ are used to reflect the antisliding stability and antioverturning stability, respectively. Due to the diversity of retaining wall types, the calculating formulas of $K_{s}$ and $K_{t}$ are not the same. However, the general formulas for $K_{s}$ and $K_{t}$ can be expressed as follows:

$$
\begin{aligned}
& K_{s}=\frac{P_{B}}{P_{A}}, \\
& K_{t}=\frac{M_{B}}{M_{A}},
\end{aligned}
$$

where $P_{A}$ and $P_{B}$ are the sliding force and antisliding force on the retaining wall, respectively, and $M_{A}$ and $M_{B}$ are the sliding moment and antisliding moment on the wall, respectively, as shown in Figure 3.

In light of the Code Design for Building Foundation (China), the stable state of a retaining wall can be divided into three levels [32]:

(1) The wall is in a stable state, when $K_{s} \geqslant 1.3$ and $K_{t} \geqslant$ 1.6 .

(2) The wall is in a essentially stable state, when $1.0 \leq$ $K_{s}<1.3$ or $1.0 \leq K_{t}<1.6$.

(3) The wall is in an unstable state, when $K_{s}<1.0$ or $K_{t}<$ 1.0 .

From (18) and (19), the stability of the retaining wall changes with a variation in earth pressure.

\subsection{Relationship between the Earth Pressure and Coefficient of} Subgrade Reaction. Here, to simplify the complexity of issues, it is assumed that no external loads or constant loads are applied to the backfill and wall. Additionally, the effects of water pressure on the wall are ignored. The distribution of the earth pressure is linear. In light of the literature [23], the stress state of the wall-soil system under low strain excitations can be equivalent to that under static equilibrium. Under low strain excitations, the mechanical analysis of a microunit of backfill is as shown in Figure 4, where $z$ is the depth of the microunit, $P_{0}$ is the initial earth pressure, $e_{0}$ is the initial void ratio, $L_{0}$ is the initial length of the microunit, $V_{S}$ is the volume of the microunit, and $V_{V 0}$ is the initial volume of the void. When the earth pressure varies from $P_{0}$ to $P_{i}$, the length of the microunit varies from $L_{0}$ to $L_{i}$, the void ratio varies from $e_{0}$ to $e_{i}$, and the void volume varies from $V_{V 0}$ to $V_{V i}$.

In light of the soil mechanic principle [33], $e_{0}$ and $e_{i}$ can be, respectively, expressed as follows:

$$
\begin{gathered}
e_{0}=\frac{V_{V 0}}{V_{S}}=L_{0} \cdot S=L_{0}, \\
e_{i}=\frac{V_{V i}}{V_{S}}=L_{i} \cdot S=L_{i},
\end{gathered}
$$

where $S$ is the cross-sectional area of the microunit. According to the soil mechanic principle [33], let $S=1, V_{S}=1$. The compression deformation $\Delta L_{i}$ can be expressed as follows:

$$
\Delta L_{i}=\left|L_{i}-L_{0}\right|=e_{0}-e_{i}
$$

The earth pressure increment $\Delta P_{i}$ can be expressed as follows:

$$
\Delta P_{i}=P_{i}-P_{0}
$$

According to definition of the compression index $C_{c}$ [33], $C_{c}$ of the backfill is expressed as follows:

$$
C_{c}=\frac{e_{0}-e_{i}}{\lg P_{i}-\lg P_{0}} .
$$

The $e-\lg P$ curve is similar to a straight line (curve (bc)) when the backfill is compressed sufficiently, as shown in Figure 5.

$C_{c}$ is the slope of this straight line, so $C_{c}$ is a constant. After substituting (21) into (23), the following is obtained:

$$
C_{c}=\frac{\Delta L_{i}}{\lg P_{i}-\lg P_{0}} .
$$

According to the assumption above, the earth pressures can be equivalent to a series of spring components. The spring stiffness is equivalent to the coefficient of subgrade reaction $K_{S}$. Therefore, (22) can be rewritten as follows:

$$
P_{i}-P_{0}=K_{S} \cdot \Delta L_{i}
$$

Substituting (22) into (25), the following is obtained:

$$
P_{i}-P_{0}=K_{S} \cdot C_{c}\left(\lg P_{i}-\lg P_{0}\right) .
$$

Then, (26) can be rewritten as

$$
\frac{P_{i}-P_{0}}{\lg \left(P_{i} / P_{0}\right)}=C_{c} \cdot K_{S} .
$$

As mentioned above, $K_{S}=K_{S 0} \cdot z^{t}$.

Thus, (27) can be rewritten as

$$
\frac{P_{i}-P_{0}}{\lg \left(P_{i} / P_{0}\right)}=C_{c} \cdot K_{S 0} \cdot z^{t}
$$



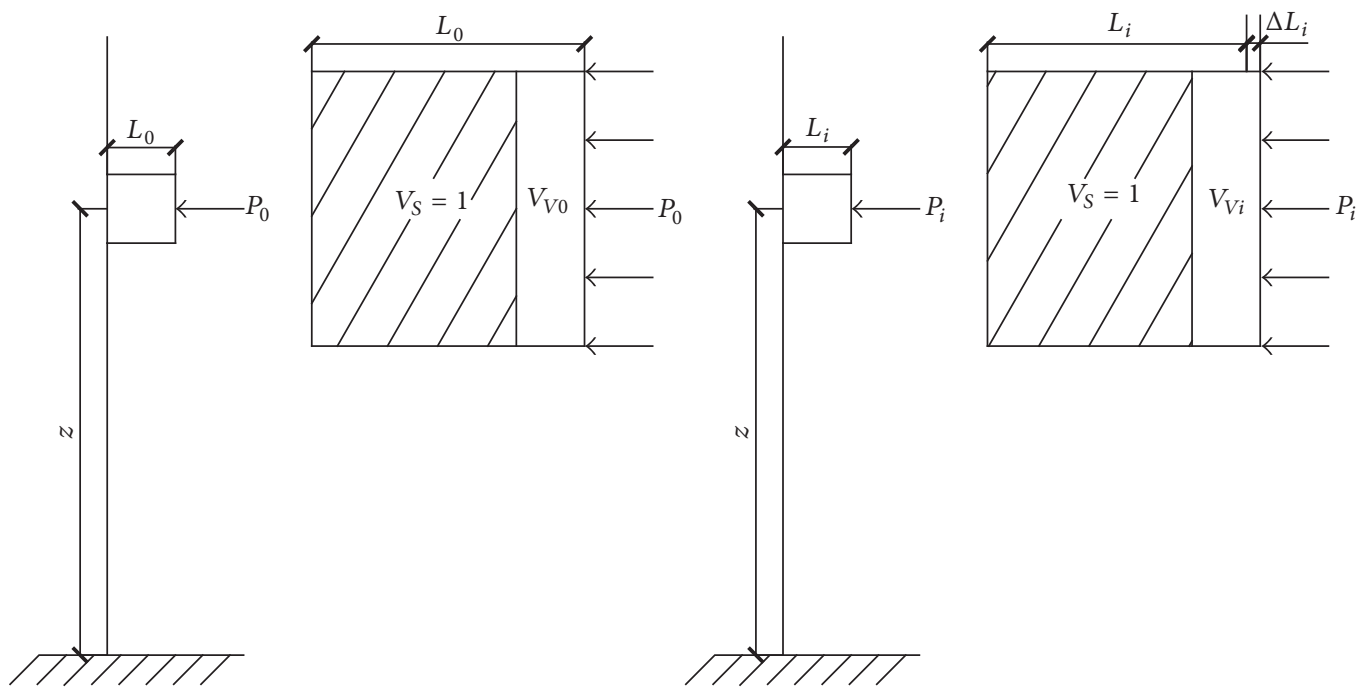

FIgURE 4: Earth pressure on the retaining wall.

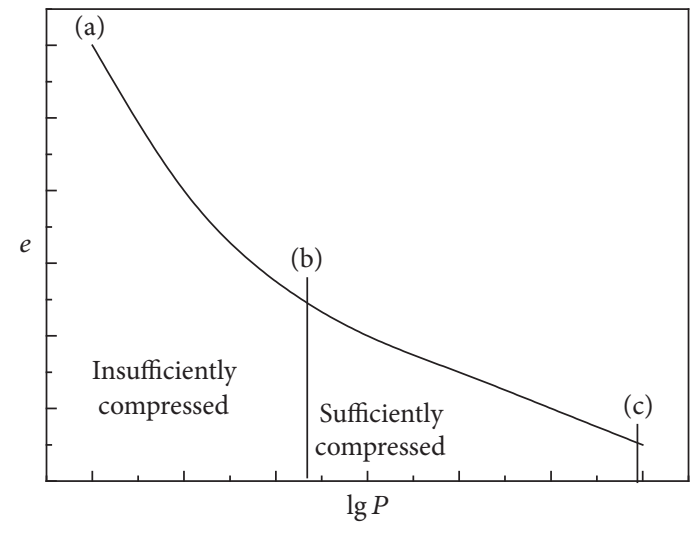

Figure 5: Schematic of the $e$ - $\lg P$ curve.

After simplification, the following can be obtained:

$$
\frac{10^{P_{i}}}{P_{i}}=\frac{10^{\left(C_{c} \cdot K_{S}+P_{0}\right)}}{P_{0}}=\frac{10^{\left(C_{c} \cdot K_{S 0} \cdot z^{t}+P_{0}\right)}}{P_{0}} .
$$

In light of (29), the earth pressure is a function of the coefficient of the subgrade reaction when the backfill is greatly compressed.

5.3. Relationships among the Damage Alarming Index, Earth Pressure, and Damage Stability of the Retaining Wall. According to (29), variation in the coefficient of subgrade reaction $K_{S}$ causes variation in earth pressure $P_{i}$ because $P_{i}$ is a function of $K_{S}$. From (18) and (19), the variation in earth pressure causes changes to the stability of the retaining wall. Additionally, the variation in $K_{S}$ causes changes to virtual impulse response functions of the retaining wall-soil coupling system because $K_{S}$ is a parameter of the baseline finite element model of the wall. Then, variation in virtual impulse response functions causes changes in the alarming index, as shown in Figure 6. The retaining wall will reach a critical stable state when the alarming index reaches the threshold value. Consequently, the alarming index ERSD can be used to detect the damage stability of this retaining wall.

\section{Examples}

A pile plate retaining wall, which is used to verify the feasibility and validity of this alarming method, is a concrete wall (concrete strength grade is C30), as shown in Figure 7(a). The height of the wall is $2.2 \mathrm{~m}$, the length is $3.0 \mathrm{~m}$, and the thickness is $0.2 \mathrm{~m}$. The foundation of the wall is anchored in backfill, and the anchored depth is $0.6 \mathrm{~m}$. The backfill behind the wall is sand, and the soil in front of the wall is miscellaneous fill. Material parameters of the wall and backfill are shown in Table 1. After a mechanical analysis of this retaining wall-soil coupling system is performed, a simplified mechanical model of this wall-soil system is created as shown in Figure 7(b), where $k_{i}$ is the stiffness coefficient of the spring and $m_{i}$ is the mass of the backfill [26].

Based on the simplified mechanical model, a finite element model of this retaining wall-soil system is established by the ANSYS program, as shown in Figure 8(a). Based on modal tests and finite element modal analysis, the parameters $\left(K_{S 0}, t\right.$, $\left.p, M_{S}, S, \alpha_{S}, \beta_{S}\right)$ of this model are updated. The modal test is as shown in Figure 8(b), where the exciting equipment is the DFC-2 hammer, as shown in Figure 9(a). The sensors are $941 \mathrm{~B}$ accelerometers, which are used to record acceleration signals. The frequency range of this sensor is $0.17 \sim 100 \mathrm{~Hz}$, and the sensitivity is $0.3\left(\mathrm{~V} \cdot \mathrm{s}^{2} / \mathrm{m}\right)$. These sensors are fixed on the wall by a binder, as shown in Figure 9(b). The signal collecting system is the JM3863A wireless vibration test system, as shown in Figure 9(c). The signals collected by the JM3863A wireless vibration test system are transmitted to a computer by the JM1802 gateway, as shown in Figure 9(d). Twenty-five measuring points are placed on the wall to obtain sufficient modal information (frequencies or mode shapes), as shown in Figure 8(b). 


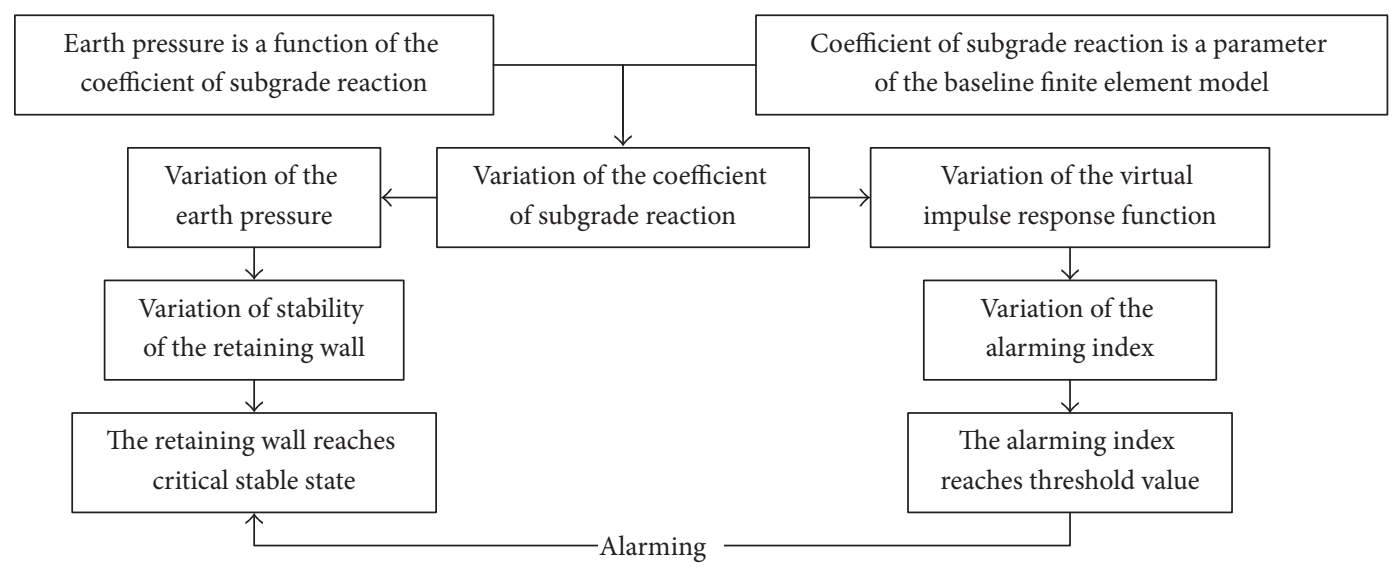

FIGURE 6: Principle of the damage stability alarm for the retaining wall.

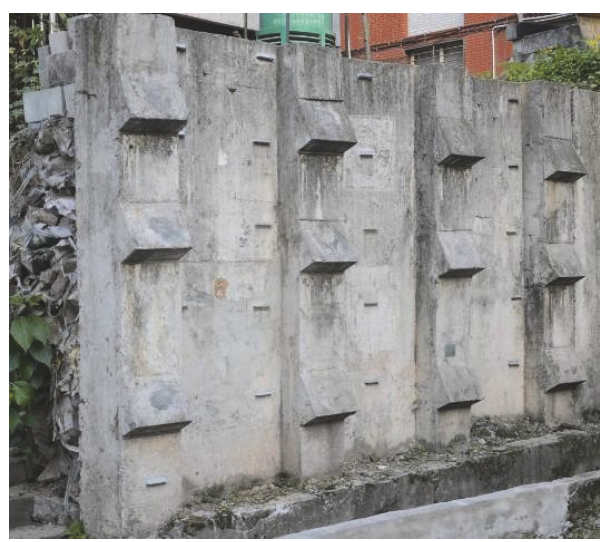

(a) Pile plate retaining wall

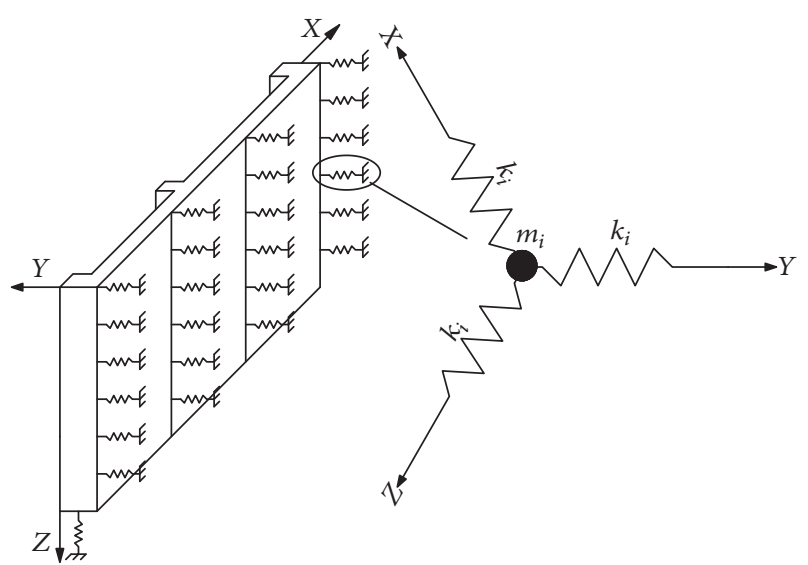

(b) Simplified mechanical model of the wall-soil system

FIGURE 7: Pile plate retaining wall-soil system.

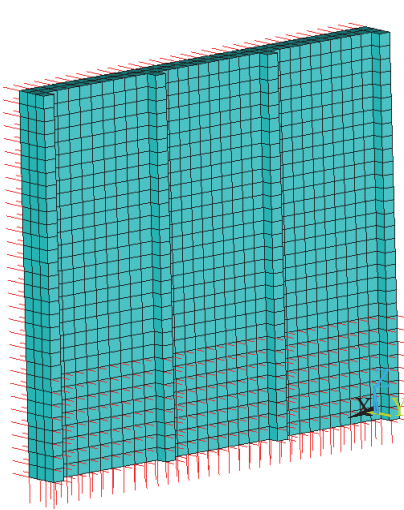

(a) Finite element model of the wallsoil system

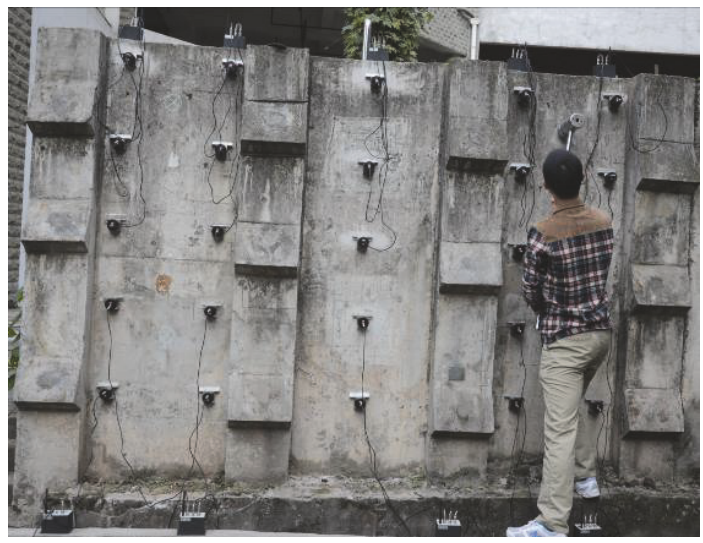

(b) Modal tests

FIGURE 8: Baseline finite element model of the pile plate retaining wall-soil coupling system. 


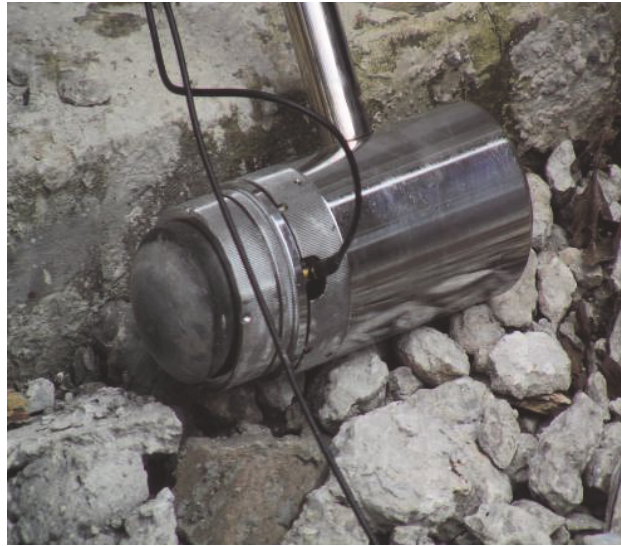

(a) DFC-2 exciting hammer

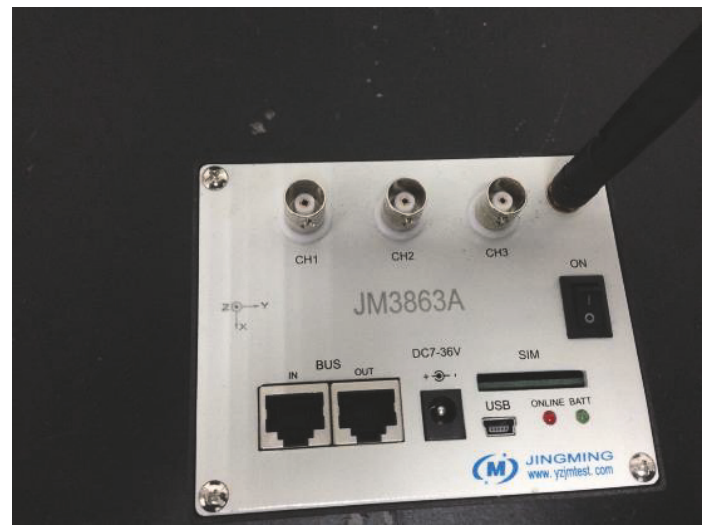

(c) JM3863A vibration test system

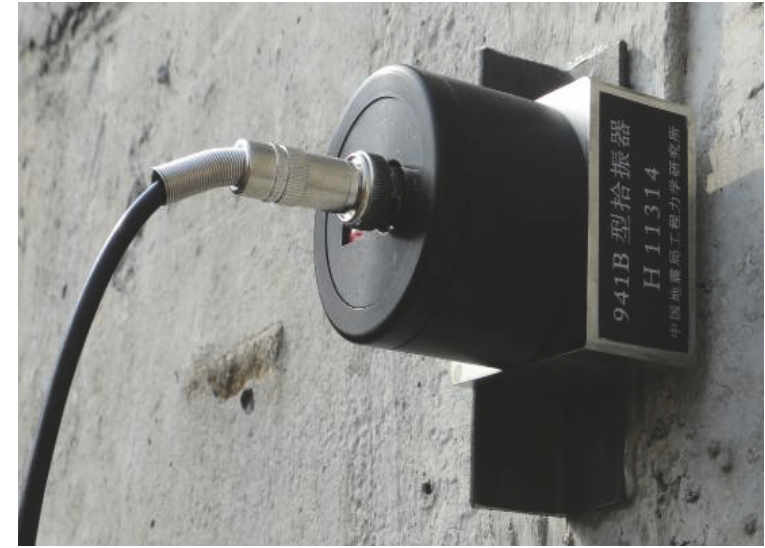

(b) $941 B$ sensor

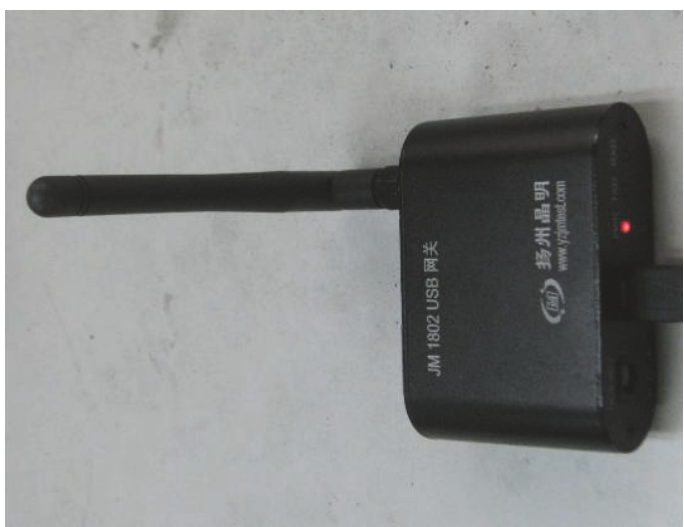

(d) JM1802 wireless gateway

FIGURE 9: Equipment for the vibration tests.

TABLE 1: Material parameters of the concrete and backfill.

\begin{tabular}{lccccc}
\hline Material & Density $/\left(\mathrm{kg} / \mathrm{m}^{3}\right)$ & $\begin{array}{c}\text { Elasticity } \\
\text { modulus } / \mathrm{MPa}\end{array}$ & Poisson' ratio & $\begin{array}{c}\text { Cohesive } \\
\text { force } / \mathrm{kPa}\end{array}$ & $\begin{array}{c}\text { Internal friction } \\
\text { angle } /{ }^{\circ}\end{array}$ \\
\hline Concrete & 2500 & $2.11 \times 10^{4}$ & 0.2 & $/$ & $/$ \\
Backfill behind the wall & 1901 & 15.4 & 0.3 & 0 & 37.6 \\
Backfill in front of the wall & 2385 & $2.3 \times 10^{4}$ & 0.2 & 460 & 39.5 \\
\hline
\end{tabular}

Here, the objective function is based on inherent frequencies of the wall-soil systems, and the design variables are undetermined parameters $\left(K_{S 0}, t, p, M_{S}, S, \alpha_{S}, \beta_{S}\right)$. The objective function Fit $(\mathbf{X})$, which is based on inherent frequency, can be expressed as

$$
\operatorname{Fit}(\mathbf{X})=\sum_{i=1}^{n}\left(\omega_{i}-\widetilde{\omega}_{i}\right)^{2} \quad \mathbf{X} \in(\boldsymbol{\Theta}),
$$

where $\mathbf{X}$ is a vector on undetermined parameters, $n$ is the number of modal orders, $\omega_{i}$ is the $i$ th modal frequency by the modal test, and $\widetilde{\omega}_{i}$ is the $i$ th modal frequency by the element modal analysis. In this paper, let $n=5$.

Initial values of the design variables $\left(K_{S 0}, t, p, M_{S}, S, \alpha_{S}\right.$, and $\left.\beta_{S}\right)$ are $2 \mathrm{e} 7,1,0.5,50,0.5,0.5$, and 0.005 , respectively. After the finite model updating, the design variables $\left(K_{S 0}\right.$, $t, p, M_{S}, S, \alpha_{S}$, and $\beta_{S}$ ) reach optimum values (2.16e7, 1.11,
$0.67,55.08,0.6371,0.4981$, and $8.81 \mathrm{e}-4)$ when the objective function, which is based on modal frequencies, reaches its minimum value $(1.67 \mathrm{e}-9)$. The finite element model based on these optimum parameters is referred to as the baseline finite element model of this pile plate retaining wall-soil coupling system.

To date, there is no calculation formula for the safety factors of the pile plate retaining wall in current codes (China). According to the literature $[26,32], K_{s}$ and $K_{t}$ can be expressed as follows:

$$
\begin{aligned}
& K_{s}=\frac{P_{B}}{P_{A}} \\
& K_{t}=\frac{P_{B} \cdot B}{P_{A} \cdot A},
\end{aligned}
$$




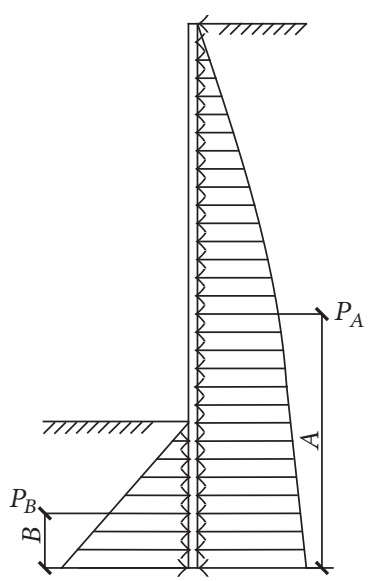

Figure 10: Schematic of the stability analysis of the pile plate retaining wall.

where $P_{A}$ is a resultant force (sliding force) on the retaining wall back; $A$ is the distance between the resultant force point and wall toe; $P_{B}$ is a resultant force (antisliding force) on the retaining wall front; $B$ is the distance between the resultant force point and wall toe, as shown in Figure 10.

The alarming index ERSD is used as an alarm for the damage stability of this retaining wall. First, the initial stability of this wall is analyzed. The initial earth pressure $P_{0}$ is known via the finite element model updating. According to (18), the initial antisliding safety factor $K_{s}$ can be expressed as follows:

$$
K_{s}=\frac{P_{B}}{P_{A}}=\frac{1951 \mathrm{kN}}{152 \mathrm{kN}}=12.84,
$$

and according to (19), the initial antioverturning safety factor $K_{t}$ can be expressed as follows:

$$
K_{t}=\frac{P_{B} \cdot B}{P_{A} \cdot A}=\frac{1951 \times 0.2}{152 \times 0.93}=2.76 .
$$

In light of the literature [32], the initial stable state of this retaining wall is stable due to $K_{s}=12.84>1.3$ and $K_{t}=2.76$ $>1.6$.

In light of the literature [23], collapse or stability loss of retaining wall structures is caused by damage in the wall, backfill, and anchoring section. Generally, damage in the wall never leads to wall collapse, whereas damage in the backfill or anchoring section is the main cause for collapse of retaining wall structures. The additional stiffness will change when the backfill or anchoring section is damaged under operation conditions. The variation in additional stiffness leads to the changes in earth pressure, which causes variation in the stability of the retaining wall under operation conditions. At the same time, changes in the additional stiffness causes a variation in the alarming index, which is based on the virtual impulse response function of responses to the baseline finite element model of the wall-soil system because the normal additional stiffness $\left(K^{n}=K_{S}\right)$ is a parameter of the baseline finite element model of the wall-soil system. The retaining wall reaches a critical stable state when the alarming index

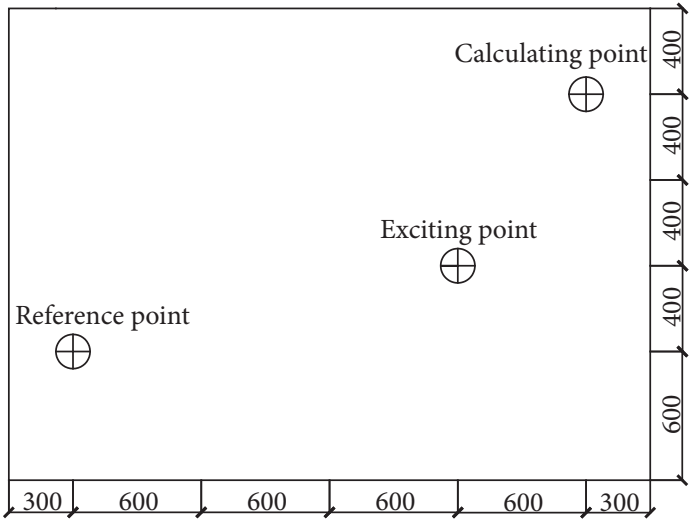

FIGURE 11: Schematic of the measurement and excitation points (unit: $\mathrm{mm}$ ).

reaches the threshold value. Thus, the next alarm for damage stability of the retaining wall is caused by damage in the backfill and anchoring section, respectively, under operation conditions.

6.1. Alarming for Damage Stability of the Retaining Wall due to Damage in the Backfill. Based on the baseline finite element model of this pile plate retaining wall-soil coupling system, damage in the backfill can be simulated by changing the coefficient of subgrade reaction $K_{S}$. Additionally, eight damage cases are listed in Table 2. To record dynamic response signals, two measuring points are assigned on the wall, as shown in Figure 11.

Via wavelet packet decomposition of the virtual impulse responses function of responses at the reference point and calculating point, the wavelet packet frequency band energy spectrum is obtained. The wavelet packet feature frequency band vector spectrum is created. Then, the wavelet packet damage feature vector spectrum is acquired. The alarming index is obtained from (17). With the increased coefficient of subgrade reaction, the alarming index values increase, but the safety factor values decrease. The antisliding safety factor $K_{s} \geqslant 1.3$ and the antioverturning safety factor $K_{t} \geqslant 1.6$ when the alarming index ERSD $<8.924$. According to the Code Design for Building Foundation (China) [32], the retaining wall is in a stable state when ERSD $<8.924 . K_{s} \geqslant 1.3$ and $1.3<K_{t}<1.6$ when $8.924 \leqslant$ ERSD $<19.810$. Thus, the retaining wall is essentially in a stable state when $8.924 \leqslant$ ERSD $<19.810 . K_{s} \geqslant 1.3$ but $K_{t}<1.0$ when ERSD $\geqslant 19.810$. Thus, the retaining wall is in an unstable state, as shown in Figure 12.

6.2. Alarming for Damage Stability of the Retaining Wall due to Damage in the Anchoring Section. As mentioned above, damage in the anchoring section can also be simulated by a decrease in additional stiffness, which is relevant to the coefficient of subgrade reaction $K_{S}$. Six cases are simulated, as listed in Table 3. With the decreased coefficient of subgrade reaction, the alarming index values increase but the safety factor values decrease. The antisliding safety factor $K_{s} \geqslant 1.3$ and the antioverturning safety factor $K_{t} \geqslant 1.6$ when the 
TABle 2: Damage cases.

\begin{tabular}{lcccccccc}
\hline Case & Case 1 & Case 2 & Case 3 & Case 4 & Case 5 & Case 6 & Case 7 & Case 8 \\
\hline$K_{S 0} /\left(\mathrm{kN} / \mathrm{m}^{3}\right)$ & $2.5 \mathrm{e} 4$ & $3.0 \mathrm{e} 4$ & $3.5 \mathrm{e} 4$ & $4.0 \mathrm{e} 4$ & $4.5 \mathrm{e} 4$ & $5.0 \mathrm{e} 4$ & $5.5 \mathrm{e} 4$ & $6.0 \mathrm{e} 4$ \\
\hline
\end{tabular}

TABle 3: Damage cases.

\begin{tabular}{lcccccc}
\hline Cases & Case 1 & Case 2 & Case 3 & Case 4 & Case 5 & Case 6 \\
\hline$K_{S 0} /\left(\mathrm{kN} / \mathrm{m}^{3}\right)$ & $2.0 \mathrm{e} 4$ & $1.8 \mathrm{e} 4$ & $1.6 \mathrm{e} 4$ & $1.4 \mathrm{e} 4$ & $1.2 \mathrm{e} 4$ & $1.0 \mathrm{e} 4$ \\
\hline
\end{tabular}

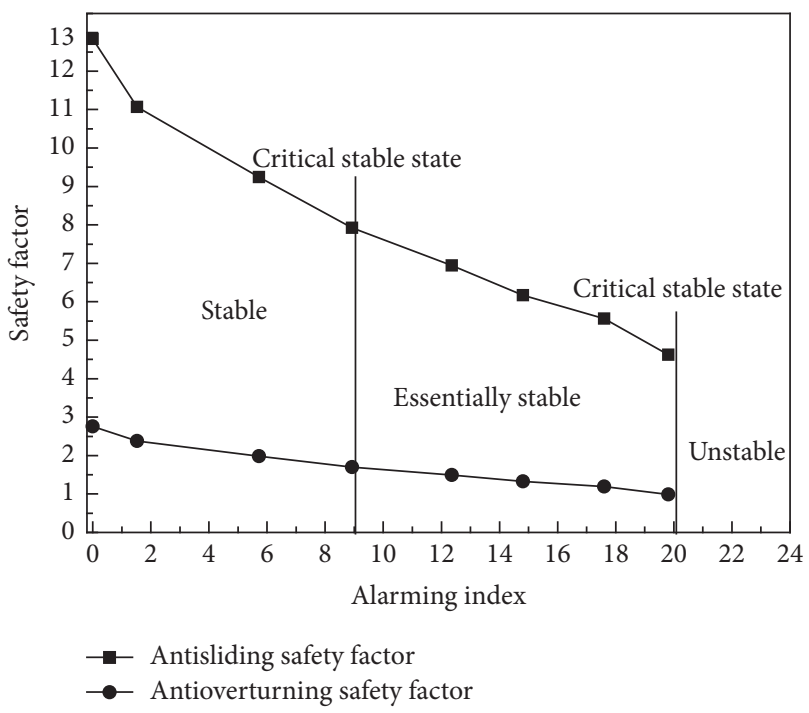

FIGURE 12: Curve of alarming index-damage stability of the retaining wall (damage in the backfill).

alarming index ERSD $<9.503$. Thus, the retaining wall is in a stable state. $K_{s} \geqslant 1.3$ and $1.3<K_{t}<1.6$ when $9.503 \leqslant$ ERSD $<20.942$. Thus, the retaining wall is essentially in a stable state. $K_{s} \geqslant 1.3$ but $K_{t}<1.0$ when ERSD $\geqslant 20.942$. Thus, the retaining wall is in an unstable state, as shown in Figure 13.

\section{Discussion}

Due to the diversity of the retaining wall types, the simplified mechanical model of the retaining wall-soil coupling system, baseline finite element model of the wall-soil system, and calculation formulas for the safety factors (including antisliding safety factor and antioverturning safety factor) are not the same. However, the principle of damage stability alarming for retaining walls is the same. Thus, the damage stability of different types of retaining walls can also be alarmed by this stability alarming method. However, there are certain limitations to this alarming method.

(1) It is assumed that no external loads or constant loads are applied to the backfill and the wall with the relationship between earth pressure and coefficient of subgrade reaction. However, this method may be not suitable when the external loads are variable.

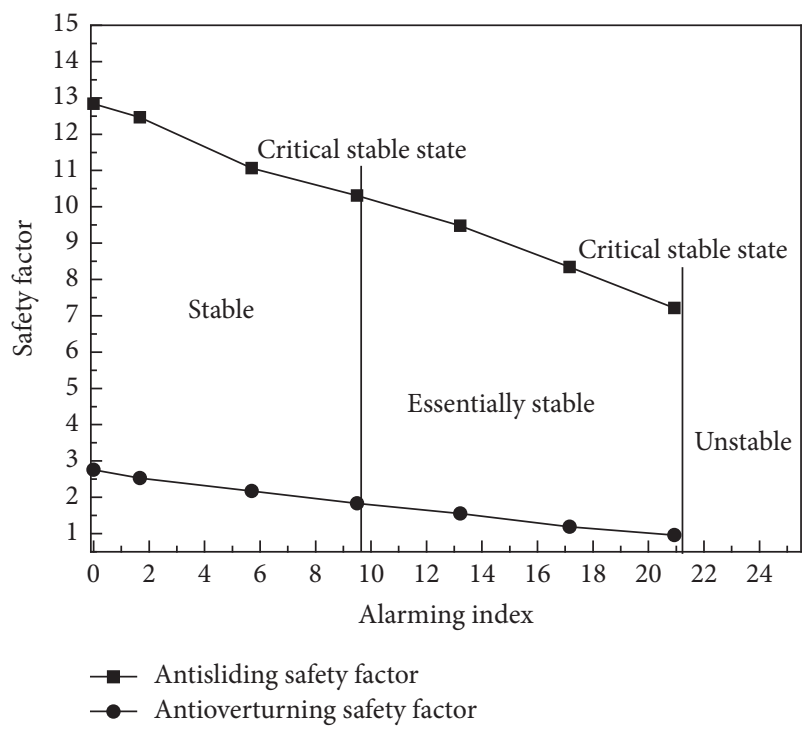

FIGURE 13: Curve of alarming index-damage stability of the retaining wall (damage in the anchoring section).

(2) It is assumed that the effects of water pressure on the wall are not considered. Thus, this method is suitable for the condition that the water content in the backfill is low. This method is not suitable when the backfill water content is high.

(3) It is assumed that the distribution of the earth pressure is linear. In practice, linear earth pressure is rare. The classical Rankine's earth pressure theory or Coulomb's earth pressure theory may be more suitable when the earth pressure on the wall is calculated.

(4) According to the soil mechanic principle [33], the compression index $C_{c}$ is a constant when the backfill is compressed sufficiently. The $e-\lg P$ curve is a straight line (curve (bc) in Figure 5), and the earth pressure is a function of one variable coefficient of subgrade reaction. Based on the coefficient of the subgrade reaction, the relationships among the alarming index, earth pressure, and damage stability of the retaining walls are analyzed. The alarming index can be used as an alarm for the damage stability of retaining wall structures. Nevertheless, the compression index $C_{c}$ is a variable when the backfill is compressed insufficiently. The $e-\lg P$ curve is no longer a straight line (curve (ab) in Figure 5), and the earth pressure is a function of two variables: the coefficient of subgrade reaction and the compression index. Under this condition, this method is not suitable for 
the damage stability alarming for retaining walls. Thus, this alarming method is suitable only for the backfill, which is compressed sufficiently.

(5) In this work, the feasibility and validity of this method are verified only by numerical tests. Further investigation of damage stability alarming for retaining wall structures via field tests is still necessary in the future.

\section{Conclusions}

In this paper, the effects of damage emerging from a retaining wall-soil system on stability of the wall are investigated without considering the effects of other factors (such as external loads or water pressure) on the stability of the wall. On the basis of mechanical analysis, finite element model updating, and wavelet packet damage alarming theory, the influences of damage within retaining walls on stability of the wall are examined.

Via a mechanical analysis of the retaining wall-soil system, the interaction between the wall and backfill is equivalent to additional stiffness. The backfill is equivalent to additional mass. Next, a simplified mechanical model of this retaining wall-soil system is acquired. Based on this simplified mechanical model, a finite element model of the retaining wall-soil system is established. Via modal tests and finite element modal analysis, a baseline finite model of this retaining wall-soil system is obtained. Based on a virtual impulse response function of dynamic responses to this baseline finite model, a damage alarming index ERSD is proposed. Then, the relationship between the earth pressure and coefficient of subgrade reaction is analyzed. It is demonstrated that the earth pressure is a function of the coefficient of subgrade reaction. Based on the finite element model updating and alarming index, the relationship between the alarming index and coefficient of subgrade reaction is analyzed. It is shown that the alarming index is determined by the coefficient of subgrade reaction. Thus, it is though the coefficient of subgrade reaction that the damage alarming index, earth pressure, and stability of the retaining wall are related. Damage emerging from walls will reduce the stability of retaining walls. Consequently, a damage stability alarming method for retaining wall structures is proposed. The damage stability of a pile plate retaining wall is alarmed via this alarming method. With an increased alarming index, the stability of the wall reduces gradually. The wall reaches a critical stable state when the alarming index reaches its threshold value. Thus, this alarming method can be used as an alarm for damage stability of retaining wall structures.

As an alarm for the stability of the retaining wall-soil system with damage, the external loads on the wall or backfill are assumed to be constant, the distribution of earth pressure on the wall is linear, the backfill is compressed sufficiently, and the water pressure on the wall is ignored. In practice, the external loads may be variable, the distribution of earth pressure is always nonlinear, the backfill may be compressed insufficiently, and the water pressure must be considered. Thus, the application of this stability alarming method is limited due to these assumptions.

\section{Conflicts of Interest}

The author of this paper does not have any conflicts of interest regarding the publication of this paper.

\section{Acknowledgments}

This study was sponsored by the Scientific Research Program funded by Shaanxi Provincial Education Department (no. 17JK0157) and the Talent Start-Up Program founded by Shaanxi University of Technology (no. SLGQD2017-4).

\section{References}

[1] S. Vijayakumer, A. B. Subhash, T. P. Sumant, M. B. Venkatesh, and L. K. Yallappa, "A case study on static stability analysis of retaining wall at dewarwadi," International Journal of Innovative Research in Science, Engineering and Technology, vol. 4, pp. 2319-8753, 2015.

[2] J.-Q. Liu and L.-W. Chen, "Numerical analysis stability of retaining wall with relieving plate," Journal of Theoretical and Applied Information Technology, vol. 48, no. 2, pp. 720-727, 2013.

[3] J.-L. Liu and L.-W. Chen, "Stability analysis of some new types of retaining wall with FEM," Information Technology Journal, vol. 12, no. 16, pp. 3626-3632, 2013.

[4] J.-Q. Liu, L.-W. Chen, and J.-L. Liu, "Stability analysis of cantilever retaining wall with FEM," Journal of Chemical and Pharmaceutical Research, vol. 5, no. 9, pp. 362-371, 2013.

[5] V. R. Tonne and P. M. Mohite, "Optimization and improvement in stability of counterfront retaining wall with relief shelf," International Journal of Research in Engineering and Technology, vol. 4, no. 4, pp. 447-451, 2015.

[6] H. Akihiro, Y. Noriyuki, S. Yoshio, K. Fujita, and T. Komatsu, "Sliding stability of dry masonry block retaining wall structure with a resistance plate," International Journal of GEOMATE, vol. 3, pp. 413-418, 2012.

[7] G. Boscato, "Comparative study on dynamic parameters and seismic demand of pultruded FRP members and structures," Composite Structures, vol. 174, pp. 399-419, 2017.

[8] G. Boscato, E. Reccia, and A. Cecchi, "Non-destructive experimentation: Dynamic identification of multi-leaf masonry walls damaged and consolidated," Composites Part B: Engineering, vol. 133, pp. 145-165, 2018.

[9] K.-H. Wang, S.-J. Ma, and W.-B. Wu, "Pseudo-dynamic analysis of overturning stability of retaining wall," Journal of Central South University of Technology (English Edition), vol. 18, no. 6, pp. 2085-2090, 2011.

[10] D. Huang and J. Liu, "Upper-bound limit analysis on seismic rotational stability of retaining wall," KSCE Journal of Civil Engineering, vol. 20, no. 7, pp. 2664-2669, 2016.

[11] J. Liu, D. Huang, C. Yang, and S. Sun, "Upper bound seismic rotational stability analysis of gravity retaining walls considering embedment depth," Journal of Central South University, vol. 22, no. 10, pp. 4083-4089, 2015.

[12] A. Pain, D. Choudhury, and S. K. Bhattacharyya, "Seismic rotational stability of gravity retaining walls by modified pseudodynamic method," Soil Dynamics and Earthquake Engineering, vol. 94, pp. 244-253, 2017.

[13] P. Anindya, C. deepankar, and B. Sriman, "Seismic stability of retaining wall-soil sliding interaction using modified pseudodynamic method," Geotechnique Letters, vol. 5, no. 1, pp. 56-61, 2015. 
[14] M. A. Syed and C. Deepankar, "Stability of waterfront retaining wall subject to pseudo-dynamic earthquake force and tsunami," Journal of Earthquake and Tsunami, vol. 2, no. 2, pp. 107-131, 2008.

[15] Y. Changwei, Z. Shixian, Z. Jianjing, and B. Junwei, "Seismic stability time-frequency analysis method of reinforced retaining wall," Mathematical Problems in Engineering, vol. 2015, Article ID 178692, 8 pages, 2015.

[16] X.-X. Zhang, S.-M. He, Q. Su, and J. Wei, "Seismic stability analysis of pre-stressed rope of anti-slide retaining wall," Geotechnical and Geological Engineering, vol. 31, no. 4, pp. 13931398, 2013.

[17] X.-P. Liu, L.-J. Su, Y. Wu, and S.-M. He, "Seismic stability of gravity retaining walls under combined horizontal and vertical accelerations," Geotechnical and Geological Engineering, vol. 33, no. 1, pp. 161-166, 2015.

[18] X.-P. Zhou, X. Ji, and Q.-H. Qian, "Stability analysis of water front retaining wall subjected to seismic loads using pseudodynamic method," Chinese Journal of Rock Mechanics and Engineering, vol. 31, no. 10, pp. 2017-2081, 2012.

[19] Y. F. Du, Y. Yu, and H. Li, "Relationship between safety factor and reliability index of retaining wall's stability," Journal of Lanzhou University of Technology, vol. 34, no. 3, pp. 113-116, 2008.

[20] M.-H. Zhao, C. Jiang, and W.-G. Cao, "Non-probabilistic reliability analysis of retaining walls based on interval theory," Yantu Gongcheng Xuebao/Chinese Journal of Geotechnical Engineering, vol. 30, no. 4, pp. 467-472, 2008.

[21] F. Song, H. Liu, H. Chai, and J. Chen, "Stability analysis of geocell-reinforced retaining walls," Geosynthetics International, vol. 24, no. 5, pp. 442-450, 2017.

[22] C. Zhang, X. Chen, and W. Fan, "Overturning stability of a rigid retaining wall for foundation pits in unsaturated soils," International Journal of Geomechanics, vol. 16, no. 4, Article ID 06015013, 2016.

[23] Q. Xu, Damage identification and alarming for pile plate retaining wall, Chongqing University, Chongqing, 2015.

[24] Q. Xu, "Damage identification investigation of retaining wall structures based on a virtual impulse response function," Shock and Vibration, vol. 2016, Article ID 1346939, 2016.

[25] Y.-X. Zhang, S.-A. Liu, and J.-G. Chen, "Influence and its application of soil on the mode of cantilever retaining wall," Journal of Civil, Architecture and Environment Engineering, vol. 31, no. 3, pp. 72-77, 2009.

[26] L.-B. Liu, Y.-X. Zhang, and J.-G. Chen, "Application of improved multi-population genetic algorithm damage identification of soil-wall system," Journal of Civil, Architecture and Environment Engineering, vol. 35, no. 3, pp. 1-6, 2013.

[27] C. Zhang, G.-Q. Song, and G.-Y. Wu, "Structure damage identification by finite element model updated with improved tikhonov regularization," Engineering Mechanics, vol. 29, no. 2, pp. 29-33, 2012 (Chinese).

[28] C. Zhang, Z.-J. Hong, and G.-Q. Song, "Structural damage identification by model updating method with 1-norm-based regularization scheme," Chinese Journal of Applied Mechanics, vol. 30, no. 5, pp. 754-761, 2013.

[29] Z. Hou, M. Noori, and R. S. Amand, "Wavelet-based approach for structural damage detection," Journal of Engineering Mechanics, vol. 126, no. 7, pp. 677-683, 2000.

[30] Y.-L. Ding and A.-Q. Li, "Parameters for identification of wavelet packet energy spectrum for structural damage alarming,"
Journal of Southeast University (Natural Science Edition), vol. 41, no. 4, pp. 824-828, 2011.

[31] Y.-L. Ding, A.-Q. Li, and Y. Deng, "Combined application of wavelet packet analysis and information fusion on structural damage alarming," Engineering Mechanics, vol. 27, no. 8, pp. 72$76,2010$.

[32] GB50007-2011, Code for Design of Building Foundation, China Building Industry Press, Beijing, China, 2011.

[33] G.-X. Li, B.-Y. Zhang, and Y.-Z. Yu, Soil Mechanics, Tsinghua University Press, Beijing, China, 2013. 


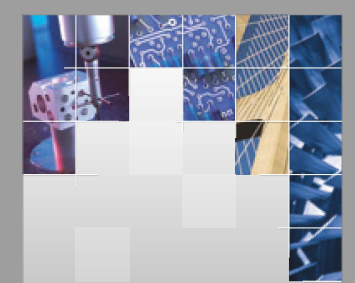

\section{Enfincering}
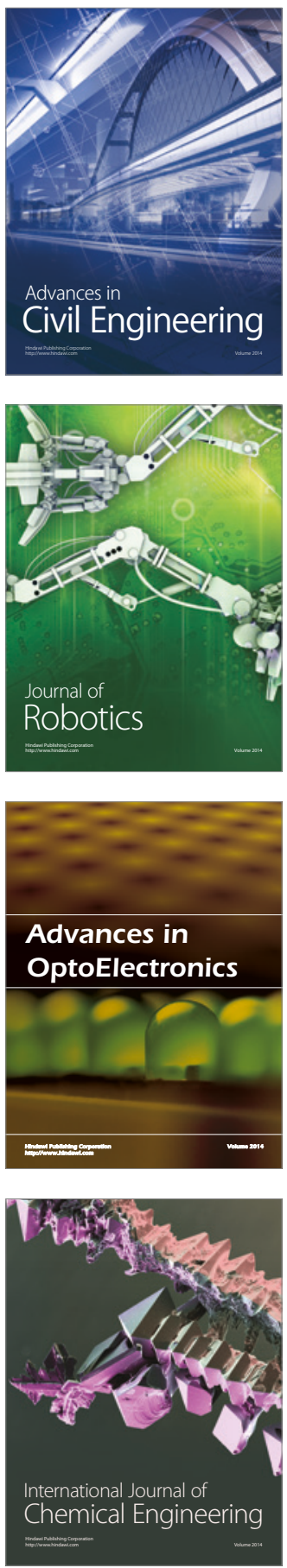

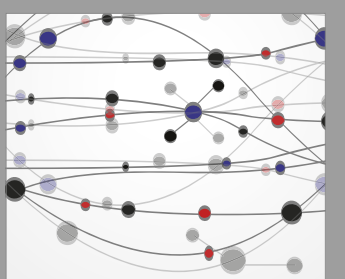

The Scientific World Journal

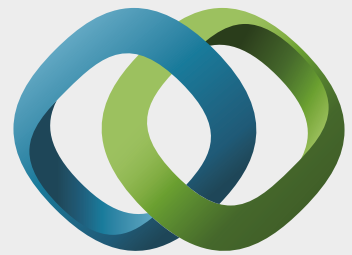

\section{Hindawi}

Submit your manuscripts at

https://www.hindawi.com
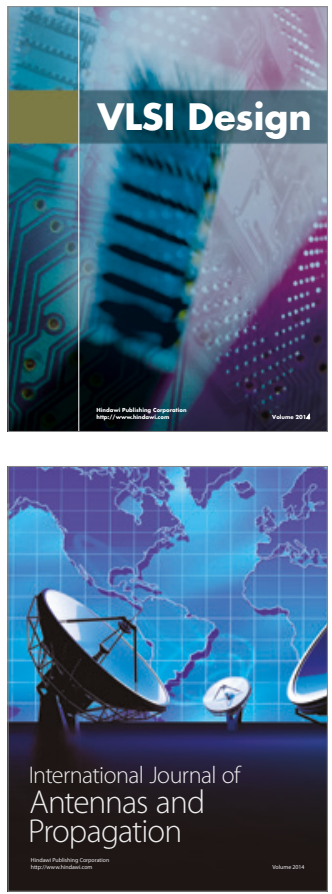

\section{Rotating}

Machinery
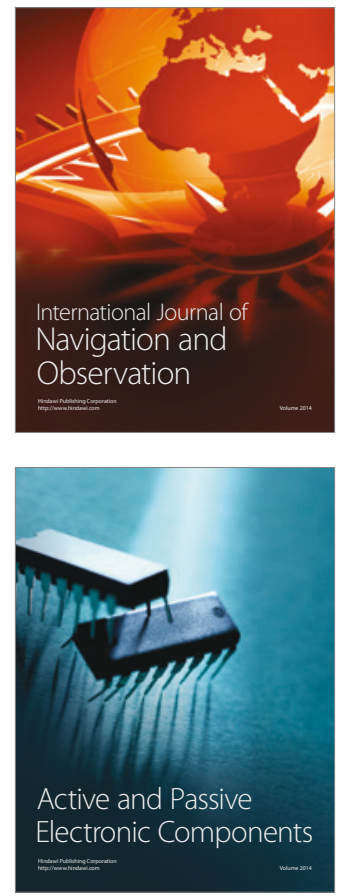
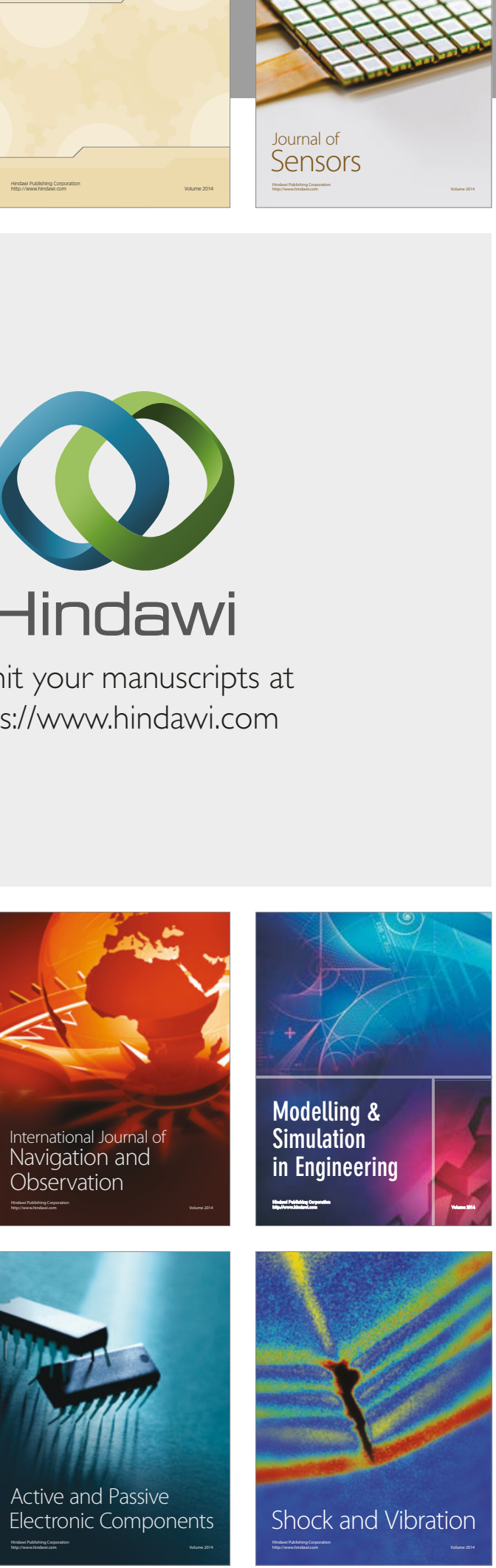
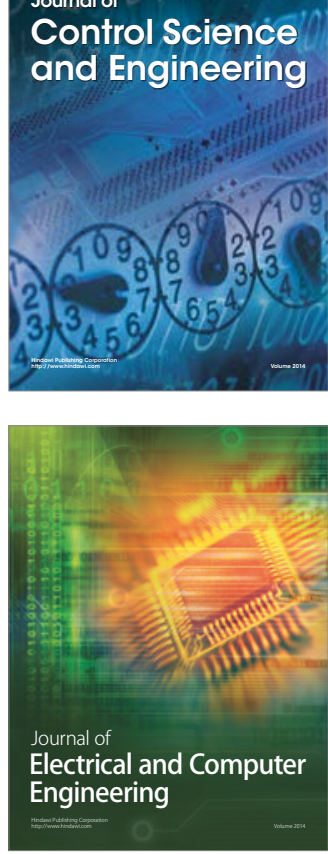

Distributed

Journal of

Control Science

and Engineering
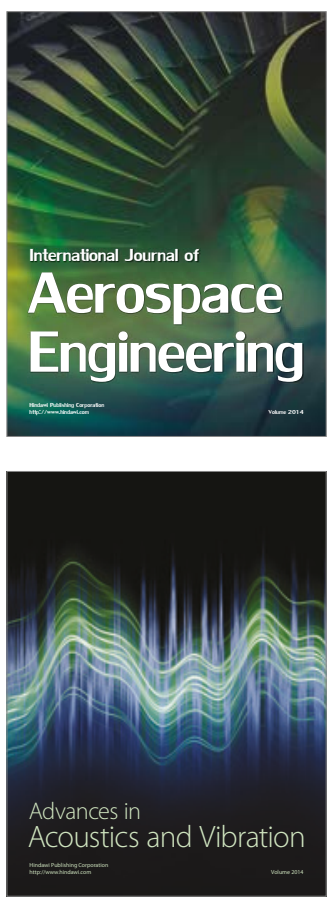

Sensor Networks 